\title{
Autoconstrução e autogestão habitacional no Brasil: um estudo comparativo em dois períodos: 1975-1986 e 2004-2018
}

Marina B. Ferreiraa,*

${ }^{\text {a}}$ Programa de pós-graduação em Urbanismo, PROURB, Universidade Federal do Rio de Janeiro, Rio de Janeiro/Brasil

\section{Informações}

Recebido 2 Outubro 2020

Manuscrito revisado recebido 8 Novembro 2020

Aceito 10 Novembro 2020

Palavras-chave

Autoconstrução

Ajuda mútua

Programas alternativos

MCMV-e.

\section{Resumo}

As políticas habitacionais direcionadas à população de baixa renda ocupam um importante espaço na agenda técnico-político da maioria dos países, sendo muitas vezes, vinculadas a práticas de ajuda mútua, autoconstrução, mutirão e autogestão. O presente artigo analisa dois períodos em que, no Brasil, essas práticas foram apoiadas e institucionalizadas a nível federal: o primeiro, entre 1975 1986, por meio dos denominados Programas Alternativos implementados pelo Banco Nacional de Habitação (BNH), e o segundo, entre 2004 - 2018, com os programas Crédito Solidário e Minha Casa Minha Vida - Entidades (MCMV-e). O estudo apresenta a relação entre esses dois períodos históricos evidenciando seus contrastes no que tange o incentivo à políticas habitacionais de fomento à autoconstrução no Brasil. A partir do estudo comparativo, percebe-se a oscilação no diálogo entre Estado e sociedade civil, bem como a forma distinta com que as noções presentes no debate são apropriadas pelos diferentes grupos sociais.

\section{Self-construction and Self-Management in Brazil. A comparative study in two periods: 1975- 1986 and 2004-2018}

\section{Article info}

Received 2 October 2020

Received in revised form 8 November 2020

Accepted 10 November 2020

\section{Keywords}

Self-construction

Mutual help

Alternative programs MCMV-e

\section{Abstract}

Housing policies aimed at the low-income population occupy an important place on the technicalpolitical agenda of most countries, and are often linked to practices of mutual aid, self-construction, collective effort and self-management. This article analyzes two periods in which, in Brazil, these practices were supported and institutionalized at the federal level: the first, between 1975 - 1986, through the so-called Alternative Programs implemented by the National Housing Bank (NHB), and the second, between 2004 - 2018, with the Crédito Solidário and Minha Casa Minha Vida - Entities (MCMV-e) programs. The study presents the relationship between these two historical periods, highlighting their contrasts in terms of encouraging housing policies to promote self-construction in Brazil. From the comparative study, there is an oscillation in the dialogue between the State and civil society, as well as the different way in which the notions present in the debate are appropriated by different social groups.

\section{Autoconstrucción y Autogestión en Brasil. Estudio comparativo en dos periodos: 1975-1986 y 2004-2018}

\section{Información}

Recibido 2 Octubre 2020

Manuscrito revisado recibido 8 Noviembre 2020

Aceptado 10 Noviembre 2020

\section{Palabras clave} Autoconstrucción Ayuda mútua Programas alternativos MCMV-e.

\section{Resumen}

Las políticas habitacionales dirigidas a la población de bajos ingresos ocupan un lugar importante en la agenda técnico-política de la mayoría de los países, y muchas veces están vinculadas a prácticas de ayuda mutua, autoconstrucción, esfuerzo colectivo y autogestión. Este artículo analiza dos períodos en los que, en Brasil, estas prácticas fueron apoyadas e institucionalizadas a nivel federal: el primero, entre 1975 - 1986, a través de los denominados Programas Alternativos implementados por el Banco Nacional de la Vivienda (BNH), y el segundo, entre 2004 - 2018, con los programas Crédito Solidário y Minha Casa Minha Vida - Entidades (MCMV-e). El estudio presenta la relación entre estos dos períodos históricos, destacando sus contrastes en términos de incentivar políticas habitacionales para promover la autoconstrucción en Brasil. A partir del estudio comparado, se observa una oscilación en el diálogo entre el Estado y la sociedad civil, así como la diferente forma en que las nociones presentes en el debate son apropiadas por diferentes grupos sociales.

\footnotetext{
* Autor correspondente em: Programa de pós-graduação em Urbanismo, PROURB, Universidade Federal do Rio de Janeiro, Rio de Janeiro/Brasil. E-mail: marina.boarettof@gmail.com (Marina B. Ferreira)
} 


\section{Introdução}

A predominância da dinâmica capitalista no contexto mundial nos leva a refletir sobre o poder de dominação desse sistema e as condições necessárias a sua sobrevivência. Um olhar atento frente aos acontecimentos atuais, apoiados na expansão do fenômeno da g lobalização, nos avanços científicos e tecnológicos e no aprofundamento das desigualdades sociais, confirma que vivemos em um momento complexo de tendências contraditórias.

Por um lado, o sistema capitalista se reinventa e se reconfigura. Novas formas de dominação são estabelecidas, cada vez mais abstratas, impulsionando processos de acumulação de capital. Por outro lado, processos sociais e políticos emergem e lutam contra ameaças e impactos do capitalismo e da globalização econômica. Alavancados por um conjunto de grupos sociais articulados, esses esforços buscam o reconhecimento, a defesa e a realização dos direitos humanos, lutando contra as formas de dominação, discriminação e exploração.

Essas contradições ganham expressão no campo da produção habitacional popular onde grupos de moradores, movimentos sociais de base, organizações sem fins lucrativos, cooperativas entre outros agentes se organizam a fim de reivindicar seus direitos como cidadãos capazes de construir, gerir e redefinir o espaço comum, construindo coletivamente soluções cujas principais estratégias partem de processos de auto-organização, democratização, participação ativa e autonomia. Dessa forma, a produção habitacional se apresenta como um campo em disputa, sendo os processos de formulação e implementação das políticas e programas habitacionais reflexos dessas tensões.

Esse artigo busca retratar essas disputas em dois momentos históricos: no primeiro, período de ditadura militar onde as políticas habitacionais de ajuda mútua são formuladas e oferecidas pelo Estado sem o envolvimento da sociedade civil; e n segundo período, onde há maior abertura de diálogo entre Estado e sociedade civil, em especial com os movimentos populares, ampliando a participação desses grupos na formulação de políticas e programas habitacionais.

\section{Autoconstrução Habitacional e Políticas de Ajuda Mútua}

\subsection{Autoconstrução habitacional como prática social}

\begin{abstract}
"A autoconstrução, o mutirão, a auto-ajuda, a ajuda mútua são termos usados para designar um processo de trabalho calcado na cooperação entre as pessoas, na troca de favores, nos compromissos familiares, diferenciando-se portanto das relações capitalistas de compra e venda da força de trabalho." (MARICATO, 1979, p. 71).
\end{abstract}

Inicialmente é importante reconhecer a autoconstrução habitacional como uma prática antiga e não como uma idéia inovadora do século XX. No contexto capitalista da sociedade atual, a autoconstrução aparece como uma estratégia de construção para uma ampla parcela da população que, desprovida de condições de acesso à moradia por meio do mercado formal, resolve sua necessidade por conta própria, providenciando diretamente a construção e gestão de suas casas.

A prática da autoconstrução deve ser compreendida como um conjunto de atividades relacionadas à construção, e não somente a construção física da unidade habitacional. A casa autoconstruída deve "ser edificada sob gerência direta do seu proprietário e morador: adquire ou ocupa o terreno; traça, sem apoio técnico, um esquema de construção; viabiliza a obtenção dos materiais; agencia a mão de obra, gratuita e/ou remunerada informalmente; e constrói sua casa." (BONDUKI, 1994, p. 258).

"O tema auto construção parte de um certo pressuposto de que a população só constrói, o que não é verdade apenas do ponto de vista físico, se colocar bloco sobre bloco e se fizer revestimentos etc. Embute a ideia de empreendimento porque é preciso arranjar um terreno para construir, épreciso mobilizar algum tipo de arranjo financeiro para comprar 0 material a prestação e para estocá-lo ao longo do tempo quando não há o financiamento, até ter todo o material comprado poder fazer um novo ciclo de construção, uma 
vez que as moradias construídas desta maneira são feitas em soluços, digamos assim. [...] Além do arranjo de mão de obra, pois a idéia de que apenas a mão de obra é do próprio morador ou da sua família é um pouco romântica dos anos 60 e 70. Na verdade esses arranjos envolvem contratação de pedreiros avulsos e de algum tipo de apoio de mão de obra especializada. Ou seja, existe um arranjo de mão de obra para o processo de produção. Neste contexto, há uma ideia de empreendimento com um conjunto de atores e fatores que atuam neste processo de produção da unidade habitacional [....".(BONDUKI, 2017, Palestra no (AU-RJ).

No campo habitacional, o termo "autoconstrução" pode assumir distintas conotações, a saber: não significa necessariamente autoconstruído ou autogerido; tem sido utilizado para caracterizar tanto esforços individuais como coletivos (mutirão); possui relação com o processo de construção da habitação de forma progressiva, em etapas, de forma incremental; está associado à um processo de construção que ocorre espontaneamente na maior parte do mundo; e, finalmente o termo é amplamente usado de forma normativa, empregado para prescrever um conjunto de políticas habitacionais pelas agências internacionais, governos centrais e demais órgãos de formulação de políticas.

\subsection{Autoconstrução habitacional como política pública}

\footnotetext{
"Entende-se a autoconstrução como política pública as propostas que colocam o Estado e o usuário em uma "ação em conjunto" em uma espécie de plataforma comum de intervenção. Nesta "parceria" se unem dois agentes que, em geral, representam interesses antagônicos e conflitantes: 0 Estado, expressão da oferta institucionalizada de moradias e o usuário, expressão da demanda de moradias." (ROSSETO, 1994, p.9).
}

As políticas de autoconstrução estão ancoradas em programas e projetos governamentais que induzem e promovem a prática da autoconstrução.
Nesse contexto o morador é incorporado ainda na fase de construção da habitação, se tornando co-autor do processo de provisão. Em geral, se configuram por meio de três tipos de programas: oferta de lotes urbanizados, dotados ou não de unidade sanitária ou unidade embrião; oferta de materiais de construção; e oferta de assistência técnica para o processo de construção.

As políticas de autoconstrução podem ser desenvolvidas de diversas maneiras, de acordo com o grau de participação e responsabilidades assumidas por diferentes grupos de atores: governo, instituições habitacionais, movimentos sociais, futuros usuários etc. Os programas e projetos podem contemplar, desde uma pequena participação do Estado, como no caso dos esquemas de "lotes e serviços" em que é oferecido apenas o financiamento de um terreno provido de infra-estrutura básica, até uma maior participação, onde para além do financiamento do terreno e da provisão de infra-estrutura, o Estado se responsabiliza pela viabilização de créditos para compra de materiais de construção e assistência técnica adequada durante todo o processo.

Para além da distribuição de responsabilidades entre os grupos envolvidos, os programas de apoio à autoconstrução assumem diferentes configurações de acordo com: a forma como o processo é conduzido, se de forma individual ou coletiva, se o grupo de moradores foi previamente organizado ou não; a existência ou não subsídios diretos e/ou indiretos; o grau de autonomia e poder de decisão dos moradores no processo; o padrão de assessoria técnica, político, pedagógica e social; etc.

Assim, trata-se de um complexo arranjo de atividades e atores, onde cada caso representa possibilidades e limitações singulares que, desencadeiam, consequentemente, processos diferenciados.

\subsection{Origens e perspectivas sobre as Políticas Habitacionais de Ajuda Mútua}

As origens das políticas de autoconstrução institucionalizada são atribuídas por diferentes 
autores a momentos distintos da história, não havendo consenso quanto a essa questão. Grande parte destes refere suas origens entre as década de 1960 e 1970, devido ao destaque que estas políticas tiveram no período, embasadas nas teorias do arquiteto inglês John F. C. Turner e nos projetos de lotes e serviços financiados pelo Banco Mundial.

Outros autores, como Richard Harris e Ray Bromley, assumem suas origens a períodos anteriores às formulações de John Turner, reconhecendo como importante contribuição as formulações de autores como Charles Abrams (1964, 1966), William Mangin (1967) e Aprodicio Lacquian (1971).

No estudo desenvolvido por Richard Harris (1998), foram identificadas diversas iniciativas implementadas anteriores à década de 1960. Segundo o autor, a ideia de que os governos poderiam ajudar famílias a construir suas próprias casas teria surgido por etapas: primeiramente, foi uma política decretada pelo governo suíço, em 1904, seguido por programas desenvolvidos pela Europa e União Soviética após a Primeira Guerra Mundial, representando uma resposta pragmática e não teorizada à grave escassez de habitação e agitação política enfrentada nesse período (HARRIS, 1998) ${ }^{1}$.

Na década de 1930, as políticas de autoconstrução institucionalizadas foram incorporadas de forma mais padronizada nas políticas de bem estar social, tanto na Europa como nos EUA, alcançando proeminência no debate público.

Durante a década de 1940, essas políticas foram implementada em Porto Rico pelo Governo dos Estados Unidos e seguido por outros países do Caribe, nos anos subsequentes. Outras nações latino-americanas, como Colômbia e Peru, além de várias colônias e ex-colônias britânicas, como Gold Coast (atualmente parte de Gana), Quênia, África do Sul e Índia, também adotaram programas de autoconstrução institucionalizada neste período (HARRIS, 1999).

$\mathrm{Na}$ década de 1950, foram realizadas experiências-piloto na Costa Rica, Chile, Guatemala, 1 Ver artigos de Richard Harris sobre as origens das políticas de autoconstrução institucionalizadas: "Slipping through the Cracks: The Origins of Aided Self-help Housing, 1918-53"; e "The silence of the experts: "Aided self-help housing", 1939-1954".
Nicarágua e Panamá (ROSSETO, 1994). A partir dessa década, os programas de autoconstrução institucionalizada começaram a ser identificados como solução para o problema da habitação para os pobres urbanos dos países em desenvolvimento. No final dos anos 1950 e início dos anos 1960, o Banco Interamericano de Desenvolvimento - BID, por meio do Programa Aliança para o Progresso, passou a financiar projetos habitacionais, incluindo projetos com base na autoconstrução além da construção de grandes conjuntos habitacionais.

Na década de 1960, as iniciativas do Estado para responder à crise habitacional eram baseadas, principalmente: 1. na construção de conjuntos habitacionais de larga escala, implementados nas franjas dos centros urbanos; 2. na política de erradicação das favelas e assentamentos, onde a prática de remoções era usual; 3. e na ausência de participação dos futuros moradores nos processos de produção da habitação.

Diante dessa conjuntura, intensificou-se um movimento crítico em relação aos grandes conjuntos habitacionais, principalmente por serem: inacessíveis às camadas mais pobres da população; 2. localizados longe de oportunidades tanto sociais quanto econômicas; 3. uma solução genérica, replicável, sem particularidades; 4. desenvolvidos sem a participação dos futuros moradores.

A frente deste movimento crítico estava o arquiteto inglês John F. C. Turner (1963, 1965, 1967, 1968a, 1969, 1972, 1976), que inspirado na capacidade de organização e construção dos moradores nos assentamentos urbanos na América Latina, defendeu a prática da autoconstrução realizada pelos pobres alegando ser mais rentável e apropriada para as necessidades e valores dessas pessoas. Segundo Turner, os esquemas de provisão habitacional pelo Estado eram caros, ineficientes e inadequados às necessidades da população.

O arquiteto, defendia que o Estado deveria desempenhar um papel de apoio, fornecendo aos grupos de baixa renda acesso aos recursos como terra, materiais e finanças (TURNER, 1968; 1972; 1976). 
“...o que estou defendendo é uma mudança radical na relação entre as pessoas e o governo, na qual o governo deixa de persistir em fazer o que faz mal ou de forma nãoeconômica - construir e gerenciar casas - e concentra-se no que tem autoridade para fazer: garantir acesso equitativo aos recursos que as comunidades locais e as pessoas não podem prover para si mesmas." (TURNER, 1976, p. 14).

Em sua visão, os assentamentos construídos pela população - "invasores" - com seus próprios esforços eram melhor adaptados às suas necessidades e circunstâncias em contraposição àqueles projetados pelo governo, onde as unidades habitacionais geralmente não atendiam às demandas e às diversas necessidades e prioridades culturais, sociais e econômicas a que se pretendiam.

O arquiteto sustentava a ideia de que as habitações deveriam ser produzidas de acordo com seu "valor de uso" - segundo definições do próprio morador de acordo com suas necessidades - e não pelo seu "valor de troca" no mercado (TURNER, 1972).

Alguns dos principais conceitos elaborados por Turner, desenvolvidos em suas publicações "Arquitetura da democracia" em 1967, "Habitação por pessoas" em 1976, "Liberdade para construir", "Habitação como um verbo" em 1972 - foram amplamente propagados, sendo o autor uma grande referência no campo da habitação social até os dias atuais.

Os argumentos influentes de Turner - baseados nos princípios de ajuda mútua - legitimaram uma mudança na política do Banco Mundial na década de 1970 e serviram como diretrizes para a construção do modelo de lotes urbanizados. A defesa da função do Estado como agente facilitador pode ser evidenciada na citação do Banco Mundial abaixo:

"Um Estado eficiente é vital para a provisão de bens, de serviços, de normas e instituições, que permitam que os mercados floresçam e que as pessoas tenham uma vida mais saudável e feliz. [...] Há cinqüenta anos a tendência era dar a entender que competia ao Estado a provisão do desenvolvimento. A nova mensagem é diferente: o Estado é essencial para o desenvolvimento econômico e social, não como promotor direto do crescimento, mas como parceiro, catalisador e facilitador." (WORLD BANK, 1997, p. 1).

Segundo Richard Harris, Turner conseguiu mudar a percepção do mundo sobre os programas de habitação por ajuda mútua como um meio alternativo de provisão habitacional de baixa renda. Dessa forma, os programas com base na autoconstrução ganharam destaque entre governos e instituições como um modelo de provisão habitacional alternativo à autoconstrução espontânea e aos esquemas estatais de construção de conjuntos habitacionais.

Em contrapartida, alguns autores como Rod Burgess $(1978,1985,1987)$, Mike Davis (2004), Emilio Pradilla (1976, 1983), Francisco de Oliveira (2006), Sérgio Ferro (2006) evidenciaram contradições e limitações presentes na abordagem da institucionalização da autoconstrução, destacando que num contexto de uma sociedade capitalista, essa prática representaria um mecanismo injusto do governo para economizar custos ao explorar as famílias pobres, inferindo um caráter exploratório sobre o trabalhador que precisa fazer horas extras de trabalho (não remuneradas) para ter acesso ao serviço habitação.

"Uma não insignificante porcentagem das residências das classes trabalhadoras foi construida pelos próprios proprietários, utilizando dias de folga, fins de semana e formas de cooperação como o 'mutirão'. Ora, a habitação, bem resultante dessa operação, se produz por trabalho não pago, isto é, supertrabalho." (OLIVEIRA, 2006, p. 59).

As habitações autoconstruídas tendem a ser mais baratas do que as fornecidas pelo Estado devido a diminuição de agentes intermediários e na redução dos custos em relação à mão de obra. Segundo esses autores, essa redução do custo da habitação contribui para a redução do valor do 
salário mínimo, já que o salário mínimo inclui o valor da habitação em seu cálculo, "desse modo, o homem autoconstrói porque ganha mal e, pelo fato de autoconstruir, seu salário é rebaixado." (BALTHAZAR, 2012, p. 58).

Esses autores, críticos à adoção da prática da autoconstrução como política pública, também consideram que a autoconstrução quando institucionalizada leva à redução do grau de responsabilidade do Estado em relação à produção habitacional, deixando o Estado de assumir o papel de provedor principal para atuar apenas como agente facilitador do processo de provisão habitacional.

Há ainda um grupo de autores tais como Nabil Bonduki, Ermínia Maricato, João Marcos Lopes, Peter Marcuse, Erhard Berner, Benedict Phillips, Jorge Fiori, Ronaldo Ramirez e Kosta Mathéy, que apoiam as políticas que se utilizam da autoconstrução, porém referem ressalvas. Consideram a questão habitacional como um problema macroestrutural mas identificam no modelo de autoconstrução institucionalizada um meio possível para redistribuição de riqueza.

Esses autores alertam que as abordagens de autoconstrução com base na recuperação total dos custos necessariamente excluem os grupos mais pobres e ampliam as desigualdades estruturais. Nesta linha de pensamento, ressaltam a necessidade das iniciativas de autoconstrução institucionalizada serem acompanhadas da oferta de assessoria técnica adequada e contínua onde seja garantida a participação efetiva das famílias.

Esses autores veem na autoconstrução institucionalizada, em contextos políticos específicos, especialmente sob processos autogestionados e coletivos, uma forma de estimular a construção de sujeitos políticos e a organização popular na defesa de seus interesses.

Assim, verificamos três principais correntes de pensamento quanto à produção habitacional baseada na autoconstrução institucionalizada: aqueles que são a favor do esquema por ajuda mútua, aqueles que são contra, e aqueles que apoiam dentro de certas condições. Vale ressaltar que essas correntes não se limitam a esses três grupos, e nem esses grupos conformam uma linha de pensamento concisa, uniforme e fechada.

Dessa forma, observa-se que o debate sobre a autoconstrução como política pública é extremamente complexo e desperta interpretações variadas com implicações de ordem política e ideológica. Vale ressaltar que na prática, a autoconstrução institucionalizada foi adotada por governos sob diferentes modelos de sociedade, incluindo tanto governos capitalistas como socialistas.

Para além das divergências encontradas nos diferentes grupo ideológico, é possível constatar uma multiplicidade de interpretações sobre os principais termos presentes no debate sobre a habitação de ajuda mútua e autoconstrução, contribuindo para ambiguidades que dificultam a análise. "Um dos maiores problemas no debate sobre a habitação por autoconstrução é que é muito difícil definir o que os proponentes entendem por autoconstrução." (BURGESS, 1978, p. 1106).

\section{Política Habitacional de Ajuda Mútua no Brasil}

\begin{abstract}
"Se o mercado de trabalho relega parte da população à pobreza, o mercado imobiliário nega aos pobres a possibilidade de habitar no mesmo espaço em que moram os que podem pagar. Surge uma demanda economicamente inviável mas socialmente inegável." (SINGER, em BONDUKI, 2013, p. 8).
\end{abstract}

No cenário das políticas habitacionais, a prática da autoconstrução foi apoiada e institucionalizada a nível federal em dois períodos: o primeiro, em 1975 - 1986, por meio dos denominados Programas Alternativos implementados pelo Banco Nacional de Habitação (BNH), e o segundo, em 2004 2018, com os programas Crédito Solidário e Minha Casa Minha Vida - Entidades (MCMV-e). Em ambos os períodos, os programas e medidas de apoio à autoconstrução surgiram como alternativas para que a camada mais pobre da população pudesse 
ser contemplada pelas políticas públicas, tendo em vista que os programas tradicionais lançados pelo governo seriam incapazes de atender essa camada de menor poder aquisitivo. Nos dois períodos os programas alternativos tiveram expressão inferior à produção habitacional hegemônica, realizada por meio dos programas tradicionais.

Apesar das diferenças existentes entre cada contexto histórico, os programas tradicionais lançados pelo BNH, na época da ditadura, bem como o programa Minha Casa Minha Vida Empresarial, lançado no governo Lula, guardam similitudes, a saber: os discursos de caráter social presentes na formulação das políticas e dos planos associados aos programas; a predominância da lógica de mercado; a difusão da propriedade individual privada; a falta de participação dos futuros moradores nos processos de decisão; os resultados visíveis no espaço urbano - baseado na produção em massa de conjuntos habitacionais espraiados nas periferias das grandes metrópoles, soluções genéricas, de baixa qualidade construtiva e espacial, carentes de equipamentos urbanos, incapazes de atender adequadamente as diversidades de arranjos familiares. Toda essa extensa produção foi orquestrada, em ambos os períodos, pela confluência entre Estado e empresas privadas do setor imobiliário e da construção civil.

Enquanto os programas tradicionais guardam semelhanças em ambos os períodos, o mesmo não acontece nos programas alternativos de ajuda mútua, que se configuram de formas distintas tanto no processo de formulação quanto na fase de implementação em cada período específico do estudo, como será retratado a seguir.

\subsection{Primeiro Período: 1975 - 1986}

Entre as décadas de 1950/1960, o país passava por mudanças estruturais caracterizadas pelo crescimento econômico, crescimento urbano e pela rápida industrialização. Nesse período, as relações campo-cidade são resignificadas, as migrações se multiplicam e o processo de urbanização se intensifica. Na medida em que se aprofundam as desigualdades sociais, a prática da autoconstrução pelos pobres urbanos configura-se como a principal alternativa para aquisição da casa própria nas grandes cidades brasileiras. "[...] as contradições entre crescimento e pobreza, acumulação e miséria, modernidade e exclusão ficam mais patentes nos modos utilizados pela população trabalhadora e sem salário para promover a moradia". (MARICATO apud LIMA, 2005, p. 124).

Na década de 1970, o momento era de crise econômica e de crise de legitimidade do governo. Após a derrota eleitoral do governo militar, em 1974, o país passava por um processo de transição democrática com uma maior mobilização da população a favor da democracia e com o fortalecimento das entidades da sociedade civil. Concomitantemente, aumentava-se a pressão e as críticas em relação a ineficiência do $\mathrm{BNH}$ quanto ao cumprimento de seus objetivos sociais. Nesse contexto, o BNH a fim de ampliar a faixa de atendimento às populações mais carentes ou de inserção instável no mercado de trabalho, adotou, como estratégia de redução dos custos da habitação, a prática da autoconstrução nas políticas habitacionais, os assim denominados Programas Alternativos. Dessa forma, as famílias de mais baixa renda, as quais em tese, se destinaria o foco da política habitacional, passam a ser relegadas aos programas marginais alternativos.

\begin{abstract}
"[...] ao tentar tratar a Autoconstrução e o Mutirão como uma Politica Habitacional, nas décadas de 70 e 80, podese dizer que a introdução das novas políticas públicas habitacionais, baseadas na proposta de autoconstrução, os projetos de mutirão e autogestão foram deixando 0 caráter de informalidade e passaram a ser enquadrados nas políticas municipais." (VIDAL, 2008, p. 151).
\end{abstract}

Pela primeira vez no Brasil, foi incorporada a prática da autoconstrução nas políticas públicas habitacionais através dos seguintes programas:

- 1975 - PROFILURB - Programa de Financiamento de Lotes Urbanizados: com o objetivo de atender às populações migrantes e de baixa renda - de zero a cinco salários mínimos, o programa previa 
a implantação de conjuntos de lotes urbanizados financiando a legalização da posse da terra e fornecendo infra-estrutura básica, reservando ao mutuário a responsabilidade de construir sua habitação de acordo com suas disponibilidades financeiras e prioridades individuais.

- 1977 - FICAM - Programa de Financiamento de Construção, Conclusão, Ampliação e Melhoria da Habitação: para as famílias com renda de até cinco salários mínimos.

- 1979 - PROMORAR - Programa de Erradicação de Subhabitação e Reurbanização de Favelas: admitia a erradicação do núcleo, ou sua urbanização, tornando-se o primeiro programa a assinalar uma mudança de postura, buscando não mais remover, mas manter os moradores em um núcleo gerado a partir da ocupação de terra.

- 1984 - PROJETO JOÃO DE BARRO - Programa Nacional de Autoconstrução. Autoconstrução por regime de Mutirão: financiava o terreno e cesta de material para construção por mutirão em cidades de pequeno porte.

Esses programas eram destinados às famílias com renda mensal de até 5 salários mínimos, enquadradas assim, no mercado popular². Esse segmento de mercado tinha como agente promotor as Companhias Habitacionais (COHABs), definidas como:

\begin{abstract}
"empresas mistas sob o controle acionário dos governos estaduais e/ou municipais, desempenham, [...] um papel análogo ao dos incorporadores imobiliários na produção de residências para as camadas de renda alta. As Cohab compete coordenar e supervisionar o trabalho das diferentes agências públicas e privadas que participam da edificação das casas populares, reduzindo o preço das unidades produzidas. Essa redução explica-se pela inexistência do "lucro do incorporador", que, em geral, eleva substancialmente o preço final da residências, enquanto que as COHABs, mesmo buscando o equilibrio financeiro, são remuneradas por uma taxa de administração." (AZEVEDO, 1988, p. 111).
\end{abstract}

2 A partir de 1974, as faixas de atendimento das COHABs foram ampliadas de modo a incluir a população cuja renda familiar fosse entre 3 e 5 SM, antes limitado a 1 e 3 SM.
A fim de receber o financiamento do $\mathrm{BNH}$, as COHABs apresentavam projetos tecnicamente compatíveis com a orientação do banco, seguindo a lógica financeiro-empresarial ${ }^{3}$. A gestão e a supervisão das construções acontecia de acordo com as prioridades estabelecidas pelos governos locais. A construção, independente do segmento de mercado, era realizada pela iniciativa privada. Apesar das Cohabs poderem legalmente assumir essa função, as mesmas não se aventuravam nessa empreitada (AZEVEDO, 1982).

Conforme diversos autores referem, com o passar do tempo, esses programas se mostraram muito aquém das expectativas e decepcionaram tanto quantitativamente quanto qualitativamente.

"O fato dos critérios financeiros prevaleceram em relação aos sociais nas definições das diretrizes das politicas habitacionais, inclusive dos programas alternativos, produziu o conceito das moradias progressivas. Um produto inacabado a ser finalizado com mão de obra do futuro morador como o produto "mais adequado" às familias de menor renda, pois só assim, diminuindo os custos e produzindo "escândalos"4, o BNH poderia efetivar esse atendimento." (ROSSETTO, 1993 apud ROYER, 2002).

Foram criticadas as práticas clientelistas quanto aos critérios de alocação dos recursos, bem como, os aspectos relacionados à qualidade das intervenções realizadas pelo PROMORAR e posteriormente pelo programa João-de-Barro. O PROMORAR, representava uma radical alteração na atuação do BNH frente às favelas, abandonando a prática das remoções em prol da manutenção daquela população em seu espaço original. Segundo Leal

3 "O custo reduzido dos projetos arquitetônicos, obtido através de uma relativa padronização das plantas residenciais, e a inexistência de despesas de comercialização (publicidade e corretagem), uma vez que, geralmente, a demanda supera em muito a oferta, são outros fatores que colaboram para a redução dos preços das unidades produzidas pelas Cohab, em comparação a casas similares vendidas no mercado sob o patrocínio de outros agentes." (AZEVEDO, 1988, p. 112).

4 Ermínia Maricato, em entrevista realizada à Revista Proposta $n^{\circ}$ 35. Rio de Janeiro: FASE-RJ, Ano XII, Set/1987, descreve que a produção feita pelo PROMORAR era de habitações de $22 \mathrm{~m}$ “... que foi um escândalo em termos de qualidade" (p.31). 
(1990), a intenção era inegavelmente meritória, e os resultados seriam desastrosos. Quanto à questão jurídica, "a regularização fundiária foi o grande óbice do programa, que teve inúmeras dificuldades para se concretizar." (ROYER, 2002, p. 14).

A respeito do programa PROFILURB, um documento de circulação interna do BNH deixava claro os objetivos do programa: "o Profilurb não se destina à remoção de favelas"5. (FJP, 1980, p. 10). Apesar dessa carta de princípios, "as experiências de lotes urbanizados já implantados indicam que, geralmente, elas surgiram para resolver problemas locais face a necessidade de remoção de favelas ou de desapropriação de áreas para implantação de projetos públicos." [...] "o imediatismo e a pressa em remover populações foram fatores determinantes na escolha de áreas que se revelaram problemáticas." (FUNDAÇÃO JOÃO PINHEIRO, 1980, p. 144). Demais fatores que contribuíram para o fracasso do programa foram a pulverização de áreas e a falta de coordenação entre os agentes (LEAL, 1990).

Nesse momento, a prática do mutirão institucionalizado não incluía a participação dos beneficiários nos processos de decisão, esses forneciam apenas a mão-de-obra para os empreendimentos. "Em alguns casos o desperdício e a má aplicação dos recursos públicos acabaram anulando a economia feita com a utilização da mão-de-obra gratuita." (VIDAL, 2008, p. 72). A descrença e a falta de experiência com a prática de mutirão gerava resistência frente a essa nova modalidade de atuação por parte das Companhias Estaduais e Municipais de Habitação (COHABs).

A idéia da participação da população diretamente envolvida com o projeto era novidade e se constituiu como um forte argumento na formulação dos Programas Alternativos. No entanto, essa participação estava circunscrita ao processo de construção do objeto edificado, traduzindo-se como mão de obra gratuita. (FUNDAÇÃO JOÃO PINHEIRO, 1980). Sobre a participação comunitária nos conjuntos, observa-se que os movimentos comunitários não foram bem desenvolvidos ou organizados:

5 Avaliação do programa PROFILURB realizada pela Fundação João Pinheiro em 1980.
"A participação da COHAB tem se limitado à fase de implantação do projeto, quando seleciona as familias e discute seus problemas, terminando no momento da comercialização, quando os Conjuntos são entregues. [...] 0 paternalismo que até o momento tem permeado a relação desses órgãos com a comunidade é preocupante, pois parece indicar a crença de que a população pobre não é capaz de se autoorganizar de maneira adequada e independente, para enfrentar os desafios que se the antepõem. A impressão que fica é a de que essas instituiçōes ajudariam muito mais se abdicassem de organizar as comunidades e permitissem a estas uma maior autonomia organizativa. Deve-se também mencionar a Taxa de Apoio Comunitário (TAC), que é acrescentada ao encargo mensal dos mutuários para promocão dessa atividade, sem que em muitos lugares a $\mathrm{COHAB}$, realize trabalhos dessa natureza." (FUNDAÇÃO JOÃO PINHEIRO, 1980, p. 166).

Diante desse quadro, a partir da década de 1980, a luta coletiva por moradia realizada por organizações da sociedade civil passa a ganhar um novo caráter e atuação com demandas e propostas alternativas, a fim de influenciar nas políticas habitacionais:

"Ao propor um programa alternativo ao do governo, o movimento por moradia ingressa num campo onde até então não participava: a interferência nas políticas públicas. Fazem crítica à politica habitacional do governo, enfatizando o desinteresse do BNH em atender às parcelas da população de mais baixa renda e aos programas habitacionais, sobretudo o PROMORAR. Criticam-se os intermediários financeiros e as empreiteiras que encarecem o custo de uma moradia que, ademais, é precária. A não consulta à população interessada é um dos aspectos mais enfatizados, considerando-se a politica adotada, além de inadequada é insuficiente para as necessidades mínimas, autoritária e paternalista." (BONDUKI, 1992, p. 41).

Nesse período, são formuladas as propostas básicas dos movimentos de luta por moradia, já incluindo a noção de que os próprios moradores 
organizados deveriam ter o controle do processo de produção das habitações. Nasce daí o embrião da autogestão no Brasil. Os movimentos sociais urbanos organizados nacionalmente têm sua origem neste período e vão se constituir nos principais movimentos de luta por moradia até os dias atuais, a saber: a Confederação Nacional das Associações de Moradores (CONAM) em 1982, a Central dos Movimentos Populares (CMP) em 1993, o Movimento Nacional de Luta pela Moradia (MNLM) em 1990, a União Nacional por Moradia Popular (UNMP) em 1993, e o Movimento dos Trabalhadores Sem Teto (MTST) em 1997.

\subsection{Entre Períodos: 1986 - 2004}

Após 22 anos de existência, o BNH é extinto pelo Decreto-Lei $n^{\circ} 2.291$, de 21 de dezembro de 1986, gerando uma descontinuidade nas políticas nacionais de habitação. Nesse momento, as principais demandas dos movimentos de moradia eram relativas a questão da terra e dos mutirões. "[...] a gente falava que queria que o Estado tivesse terra, a gente queria um financiamento diferente daquele da COHAB, a gente queria o mutirão... Mas não tinha isso muito organizado, formatado". (RODRIGUES E., 2008, apud MOREIRA, 2009, p. 52). Nesse período, a autogestão se colocava ainda de maneira incipiente, sendo assumida muito parcialmente pelos movimentos que não a tinham como palavra de ordem.

Ao longo do processo de redemocratização, o Movimento Nacional pela Reforma Urbana, criado em 1986', estimulou a discussão por meio de novos mecanismos de participação e a politização da questão urbana entre os diversos agentes sociais ligados ao campo habitacional. A atuação dos movimentos sociais foi potencializada e a defesa da autogestão incluída na agenda técnicopolítica desses movimentos ${ }^{7}$. Com o tempo, a

60 Movimento Nacional pela Reforma Urbana reuniu um grupo heterogêneo, contando com uma série de organizações da sociedade civil, movimentos, entidades de profissionais, organizações não-governamentais, sindicatos entre outros.

7 A bandeira da reforma urbana se consolida como: o direito à cidade, que se caracteriza pela gestão democrática e participativa das cidades; pelo cumprimento da função social da cidade; pela garantia da justiça social e de condições dignas a todos os habitantes das cidades; pela subordinação da pro- autogestão habitacional foi se consolidando como uma alternativa concreta para os movimentos de moradia, ampliando seu repertório de projetos e aprofundando suas reivindicações? .

\begin{abstract}
"A atuação dos movimentos sociais urbanos para a garantia do acesso à moradia digna e a demanda por recursos, programas e ações que financiassem a produção autogestionária da habitação manteve os movimentos unificados desde o processo de redemocratização e foi fundamental para a retomada dos investimentos do Estado na politica habitacional e na inclusão de associações e cooperativas como agentes proponentes e executores da política nacional de habitação." (FERREIRA, 2014, p. 25).
\end{abstract}

\subsection{Segundo Período: 2004 - 2018}

Como resultado desse longo processo de negociação, mediação e pressão social - que remonta o início da década de 1980 - o governo federal, em 2004, criou o programa Crédito Solidário voltado para a autogestão com o objetivo de financiar habitações às famílias de baixa renda organizadas em associações, cooperativas, sindicatos e demais entidades da sociedade civil organizada. Entre os anos de 2007 a 2009, foi elaborado o Plano Nacional de Habitação PlanHab - com ampla participação dos membros do Conselho das Cidades e representantes dos diversos segmentos sociais.

Em março de 2009, o Governo Federal lançou o Programa Minha Casa Minha Vida - Empresarial (PMCMV) - elaboradosema participação do Conselho das Cidades - que se propunha a construção de novas habitações priorizando as famílias de até três salários mínimos, abrangendo também aquelas

priedade à função social; e pelas sanções aos proprietários nos casos de não cumprimento da função social.

8 Em 1988, com a eleição de diversos governos municipais progressistas, de perfil democrático popular, em todo o Brasil, as experiências autogestionárias na produção de habitação de interesse social começaram a se difundir. Exemplo emblemático dessas experiências se deu em São Paulo durante o governo de Luiza Erundina com a criação do FUNAPS - Comunitário (FUNACOM). 
com renda de até dez salários mínimos. Tendo em vista o contexto da crise econômica internacional de 2009, o Programa foi concebido com o objetivo de gerar empregos e investimentos no setor da construção civil e promover o desenvolvimento econômico, reaquecendo o mercado imobiliário no Brasil.

Frente a mobilização dos movimentos de moradia, que não sentiram suas demandas contempladas pelo PMCMV, o Governo Federal criou uma modalidade específica para propiciar a participação das associações e cooperativas habitacionais autogestionárias dentro do PMCMV. Assim surge - Programa Minha Casa Minha Vida - Entidades (PMCMV-e). Apesar do programa ter incorporado algumas das propostas dos movimentos sociais, seu modelo de ação ainda continha características similares ao modelo empresarial, dificultando a execução dos projetos autogestionados pelas entidades. Dessa forma, o programa se mostrou muito aquém das demandas e das expectativas dos movimentos sociais de moradia.

"[... o programa MCMV- Entidades, com seus inúmeros normativos, não foi concebido como um programa que atenda aos princípios da autogestão: ajuda mútua, propriedade e gestão coletivas. Não há liberdade para a experimentação; os grupos são tratados de forma homogênea; a organização do grupo já é previamente definida pelas regras do programa; a propriedade em nome da associação ou cooperativa não é aceita. A gestão coletiva dos recursos por aqueles que serão os futuros moradores é uma das poucas brechas do programa que pode distinguilos dos demais." (FERREIRA, 2014, p. 200).

Infelizmente, não foram criadas as condições favoráveis e esperadas para romper com a falta de tradição de se trabalhar com a prática autogestionária no país. Assim, não podemos afirmar que exista de fato no atual governo um lugar definido na política habitacional para a autogestão. E, por isso o programa que poderia ter o potencial de surpreender os céticos e emocionar os apaixonados, resultou em frustração para aqueles que tinham a perspectiva (ou ilusão) de difundir o princípio da autogestão pelo Brasil (MOREIRA, 2009).

Ao longo dos últimos anos, os movimentos nacionais de luta por moradia foram ganhando corpo e destaque no campo da produção habitacional. As experiências acumuladas, tanto de derrotas como de conquistas, contribuíram para ampliar e fortalecer as organizações de luta, elaborando-se novos planos de ação e estratégias baseados em um modelo de produção-gestão da cidade de forma coletiva e democrática onde a prioridade é o valor-de-uso. Isso se confere na perspectiva do Movimento União Nacional de Moradia Popular (UNMP):

\begin{abstract}
"A UNMP defende a autogestão como uma maneira não só de construir casas, bairros ou equipamentos sociais, mas como uma forma de construção de poder popular. Ao controlar recursos públicos e processos, lutamos contra o clientelismo e a manipulação do poder público sobre a população e as organizações sociais. Construímos alternativas de gestão onde somos sujeitos de nossa história." (UNMP, Ofício ao Ministério das Cidades, abril de 2003).
\end{abstract}

Próximos aos movimentos sociais, novosantigos agentes passaram a participar com mais ênfase nos processos relativos à produção habitacional: entidades acadêmicas, organizações não governamentais sem fins lucrativos, fundações, vem se articulando em redes de cooperação em torno da luta pelo direito à moradia, construindo soluções alternativas de produção habitacional autogestionadas, que conduzem processos coletivos e democráticos de construção de cidade e cidadania, impulsionando, não só a construção de espaços habitáveis mas também a luta à favor do direito à moradia e à cidade.

\section{Considerações finais}

Nos diferentes contextos históricos, a abertura e a qualidade do diálogo entre Estado e sociedade civil oscilou significativamente segundo as negociações e as pressões desses grupos nos processos 
de formulação e implementação das políticas habitacionais. Essas "pressões" e suas ressonâncias se mostraram, em grande parte, em função da relação que essas organizações conseguiram estabelecer para com o poder público, além das condições e da vontade política para reconhecer, apoiar e impulsionar programas, políticas públicas e medidas que suportem essas ações.

No regime militar, era bastante limitada a participação das organizações sociais na execução das políticas habitacionais destinada a população de baixa renda. O papel de executor era desempenhado pelas instituições governamentais, sendo a produção habitacional baseada no binômio Estado - Mercado. Nesse período, a autoconstrução foi incorporada nas políticas públicas habitacionais como resposta à uma crise econômica e de legitimidade do governo militar.

Os projetos habitacionais realizados pelo governo nesse período objetivavam manter o modelo de sociedade conservador e antidemocrático baseado na ideologia da propriedade privada individual, contribuindo para inibir as reivindicações e as manifestações populares. A prática da autoconstrução incluída nos Programas Alternativos do BNH, representava, sobretudo, uma forma de reduzir substancialmente os custos de produção, sendo a "mão de obra gratuita" do trabalhador fundamental para esse objetivo, bem como a racionalidade e agilidade propiciada pelos mutirões institucionalizados - gerenciados pelas COHABs. A ideologia do "sonho da casa própria" e o estímulo à poupança, estavam associados à esses programas como uma forma de disciplinar e acalmar as massas: a casa própria, por mais pequena e sem condições que fosse, contribuia para desmobilizar e evitar que o trabalhador aderisse à manifestações e movimentos revolucionários, além de representar um bem material à família operária, um símbolo de ascensão social, crescimento econômico e valorização do trabalhador, adquirindo este, o status de proprietário dono de terra.

As organizações sociais, reprimidas no período de ditadura, se reconfiguram após a redemocratização, entre elas os movimentos populares de luta por moradia que passam a contribuir, formular, interferir e ser parte da ação pública no campo habitacional, ampliando sua atuação junto ao binômio Estado - Mercado e induzindo as políticas habitacionais na direção das transformações sociais reivindicadas pelas mesmas. Nesse contexto, a autogestão - controle sobre as tomadas de decisão durante o processo - ganha destaque e passa a ser a principal bandeira dos movimentos sociais de luta por moradia. A propriedade coletiva, apesar de pouco implementada, entra no rol de modalidades de títulos de propriedade, representando um caminho contra-hegemônico de distribuição e gestão territorial. A prática do mutirão ganha novo significado, representando não apenas o barateamento do custo da construção da habitação, mas também, um meio para o exercício de processos coletivos e democráticos que permitam a ampliação da organização popular. A contratação de empresas e/ou a remuneração dos trabalhadores no processo de produção das habitações passa a ser "norma".

A produção habitacional se apresenta como um campo de conflito entre diferentes agentes sociais que disputam a produção e a apropriação da cidade, defendendo seus interesses, nem sempre conciliáveis e, muitas vezes, contraditórios. Em cada período do estudo, as noções de mutirão, autogestão e autoconstrução ganharam significados próprios, sendo esses conceitos também objetos de disputa no campo habitacional.

Os agentes responsáveis pela condução dos processos de produção e gestão dos programas habitacionais de ajuda mútua representam grupos e interesses distintos em cada período: no período do $\mathrm{BNH}$, os agentes promotores eram as COHABs - representando os interesses dos governos locais e de certa forma do próprio $\mathrm{BNH}$; no período atual as responsáveis são entidades, cooperativas e associações representando, sobretudo, os interesses da sociedade civil.

Numa direção, os programas alternativos do $\mathrm{BNH}$, orquestrados pelas $\mathrm{COHABs}$, reproduzem o modelo hegemônico governamental de produção habitacional baseado no viés mercadológico e no caráter conservador do regime militar. A empreitada limita-se a construção da casa, não abrangendo a 
organização e emancipação política dos futuros moradores, sendo a participação desses de caráter passivo. Mantém-se assim o modelo de sociedade vigente baseado em processos individualistas, autoritários e não democráticos.

Em outra direção, os processos conduzidos pelos movimentos de luta por moradia e pelas entidades responsáveis pela implementação dos projetos - por meio do programa MCMV Entidades - representam uma ruptura quanto ao modelo de produção habitacional hegemônico: para além da construção das casas, suas ações vão ao encontro da organização e mobilização da população pela reivindicação e luta pelos seus direitos básicos, da investida na formação política dos indivíduos participantes, e da conscientização quanto às questões macroestruturais presentes. Buscam dessa forma construir novos modelos de sociedade baseados em processos coletivos, solidários e democráticos.

A intensa polarização de opiniões que atravessa esse debate reflete uma tendência à generalização e ao maniqueísmo: por um lado a visão da autogestão, autoconstrução e mutirão como espaços de utopia, por outro, vícios da virtude.

Em ambos os períodos do estudo, as políticas públicas embora tenham incluído em algum grau a autoconstrução, a autogestão e o mutirão nos programas habitacionais, os mesmos representaram esforços e processos distintos em cada momento.

Incluir esses processos na discussão do problema habitacional como um todo e principalmente no contexto histórico específico de cada período pode contribuir para diminuir ambiguidades e facilitar o estudo e a análise dessa questão.

\section{Referências bibliográficas}

AZEVEDO, S.; ANDRADE, L. A. G. Habitação e poder. Rio de Janeiro, Ed. Zahar. 1982.

AZEVEDO, S. Política de Habitação Popular: equívocos e mitos sobre a autoconstrução. Revista de Administração Municipal Rio de Janeiro, v. 36, n. 192, p. 28-39, 1989.
AZEVEDO, S. Vinte e dois anos de política de habitação popular (1964-86): criação, trajetória e extinção do BNH. Revista de Administração Pública, v. 22, n. 4, p. 107-119, jul. 1988.

BALTHAZAR, R. D. S. A permanência da autoconstrução: um estudo de sua prática no Município de Vargem Grande Paulista. 2012. Dissertação (Mestrado em Habitat) - Faculdade de Arquitetura e Urbanismo, Universidade de São Paulo, São Paulo, 2012

BERNER, E.; PHILLIPS, B. Left to their own devices? Community self-help between alternative development and neo-liberalism. Community Development Journal, v. 40, n. 1, p. 17-29, 2005.

BONDUKI, N. G. Habitação e Autoconstrução: Construindo Territórios de Utopia. Rio de Janeiro: FASE, 1992.

BONDUKI, N. G. Origens da habitação social no Brasil: o caso de São Paulo. 1994. Tese (Doutorado) - Faculdade de Arquitetura e Urbanismo, Universidade de São Paulo. São Paulo. 1994.

BONDUKI, N. G. Origens da habitação social no Brasil: arquitetura moderna, lei do inquilinato e difusão da casa própria. São Paulo: Estação Liberdade, 2013.

BURGESS, R. Self-Help Housing: A New Imperialist Strategy? A Critique of the Turner School. Antipode, v. 9 (2), p. 50-59, 1977.

BURGESS, R. Petty Commodity Housing or Dweller Control? A Critique of John Turner's Views on Housing Policy. World Development, v. 6, n. 9-10, p. 1105-1133, 1978.

BURGESS, R. Helping some to help themselves: third world housing policies and development strategies. In: MATHEY, K., Beyond self-help housing. London: Mansell Publishing, p. 75-94, 1992.

FERREIRA, R. F. C. F. Autogestão e habitação: entre a utopia e o mercado. 2014. Tese (Doutorado 
em Planejamento Urbano e Regional) - Instituto de Pesquisa e Planejamento Urbano e Regional, Universidade Federal do Rio de Janeiro. Rio de Janeiro. 2014.

FUNDAÇÃO JOÃO PINHEIRO, Diretoria de Planejamento Social e Urbano. Avaliação do PROFILURB no Brasil. Belo Horizonte: Fundação João Pinheiro, 1980.

GOHN, M. G. M. Movimentos sociais e lutas pela moradia. $1^{a}$ ed. São Paulo: Ed. Loyola, 1991.

HARRIS, R. The silence of the experts: "Aided selfhelp housing", 1939-1954. Habitat International, v. 22, n. 2, p. 165-189, 1998.

HARRIS, R. Slipping through the Cracks: The Origins of Aided Self-help Housing, 1918-53. Housing Studies, v. 14, n. 3, p. 281-309, 1999.

\section{LEAL, E. P. B. Evolução Urbana e a questão} da Habitação no Brasil: 1964-1988. 1990. 2v. Dissertação (Mestrado) - Universidade Estadual Paulista, Faculdade de Ciências e Letras de Assis. Assis, 1990.

LIMA, R. M. C. A cidade autoconstruída. 2005. Tese (Doutorado em em Planejamento Urbano e Regional) - Instituto de Pesquisa e Planejamento Urbano e Regional, Universidade Federal do Rio de Janeiro. Rio de Janeiro. 2005.

MARICATO, E. A produção capitalista da casa (e da cidade) no Brasil industrial. $2^{a}$ ed. São Paulo: Ed. Alfa-ômega, 1979.

MOREIRA, F. A. 0 lugar da autogestão no Governo Lula. 2009. Dissertação (Mestrado em Habitat) - Faculdade de Arquitetura e Urbanismo, Universidade de São Paulo, São Paulo, 2009.

NTELMA, L. J. Self-help Housing in South Africa: Paradigms, Policy and Practice. 2011. PhD Thesis - University of South Africa. 2011. acumulação capitalista no Brasil. Novos estudos CEBRAP, v. 74, p. 67-85, 2006.

RODRIGUES, E. L. A estratégia fundiária dos movimentos populares na produção autogestionária da moradia. 2013. Dissertação (Mestrado em Habitat) - Faculdade de Arquitetura e Urbanismo, Universidade de São Paulo, São Paulo, 2013.

ROSSETO, R. Organismos Internacionais e a auto-construção: análise e reflexões sobre as políticas de habitação para a população de baixa renda. 1994. Dissertação (Mestrado em Habitat) - Faculdade de Arquitetura e Urbanismo, Universidade de São Paulo, São Paulo, 1994.

ROYER, L. Política habitacional no estado de São Paulo: estudo sobre a Companhia de Desenvolvimento Habitacional e Urbano do estado de São Paulo. 2002. Dissertação (Mestrado em Habitat) - Faculdade de Arquitetura e Urbanismo, Universidade de São Paulo, São Paulo, 2002.

TURNER, J. F. C. Housing as a Verb. In: Turner, J.F.C; FICHTER, R. (Eds). Freedom to Build, dweller control of the housing process. New York: Collier Macmillan, p. 149-175, 1972.

TURNER, J. F. C. Housing by People: Towards Autonomy in Building Environments. 2nd ed. London: Marion Boyars Publishers Ltd, 2000.

VIDAL, F. E. C. A autoconstrução e o mutirão assistidos como alternativas para a produção de habitações de interesse social. 2008. Dissertação (Mestrado em Arquitetura e Urbanismo) Universidade de Brasília, Brasília, 2008.

WORLD BANK. World Development Report 1997: The state in a changing world. Oxford: Oxford University Press, 1997. 